\title{
The Sea Cucumber Body Wall Extract Promoted in Vitro Maturation of NMRI Mice Follicles at Germinal Vesicle Stage
}

\author{
Mitra Khalilzadeh, ${ }^{1}$ Javad Baharara, ${ }^{1,{ }^{*}}$ Mohsen Jalali, ${ }^{2}$ Farideh Namvar, ${ }^{3}$ and Elaheh Amini ${ }^{4}$ \\ ${ }^{1}$ Department of Biology, Faculty of Sciences, Mashhad Branch, Islamic Azad University, Mashhad, IR Iran \\ ${ }^{2}$ Montaserieh Infertility Treatment Center, Mashhad University of Medical Sciences, Mashhad, IR Iran \\ ${ }^{3}$ Institute of Tropical Forestry and Forest Products, University Putra Malaysia, Selangor, Malaysia \\ ${ }^{4}$ Department of Animal Biology, Faculty of Biological Sciences, Kharazmi University, Tehran, IR Iran \\ "Corresponding author: Javad Baharara, Department of Biology, Faculty of Sciences, Mashhad Branch, Islamic Azad University, Mashhad, IR Iran. E-mail: \\ baharara78@gmail.com
}

Received 2015 June 16; Revised 2015 July 16; Accepted 2016 July 19.

\begin{abstract}
Background: IVM (in vitro maturation) appear to be certified high pregnancy outcome. Therefore, attempt to find an appropriate culture system using natural products for increasing developmental competencies fascinating.

Objectives: This experiment is aimed to evaluate the effect of sea cucumber methanol extract on in vitro maturation of immature mouse oocyte.

Methods: In this experimental study, Preantral follicles at germinal vesicle stage were collected from 24 - 26 days NMRI female mouse ovaries and transferred to IVM medium supplemented with different concentration of sea cucumber methanol extract (5, 10, 20, $30 \mu \mathrm{g} / \mathrm{mL}$ ). Antioxidant capacity of sea cucumber extract was evaluated using DPPH (2, 2-diphenyl-1-picrylhydrazyl) assay. Further, oocyte maturation and TNF- $\alpha$ expression were recorded till day $10^{\text {th }}$. Data were analyzed by one-way analysis of variance (ANOVA) through SPSS 16.

Results: The percentage of arrested oocyte at germinal vesicle stage in the control group was significantly $(\mathrm{P}<0.05)$ higher than treated group $(20 \mu \mathrm{g} / \mathrm{mL})$. There were significant $(\mathrm{P}<0.01)$ differences in percentage of maturated oocyte to metaphase II (MII) stage between treated and control group. DPPH radical scavenging capacity and reduction of TNF- $\alpha$ expression in treated oocyte demonstrated that sea cucumber increased rate of oocyte maturation. In addition, the treated oocyte $(20 \mu \mathrm{g} / \mathrm{mL}) \mathrm{achieved} \mathrm{the}$ highest percentage of MII stage.

Conclusions: It was concluded that the sea cucumber extract with optimum concentration can improve oocyte maturation. Sea cucumber extract treatment can be suggested as a novel therapeutic strategy to be used in infertility modality in the future.
\end{abstract}

Keywords: Oocyte, In Vitro Maturation, Antioxidant, Sea Cucumber

\section{Background}

Infertility is typically determined as the inability to achieve pregnancy after one year or more of regular and UN protected coitus, so that about $8 \%-12 \%$ of couples encounter with difficulty in pregnancy around the world [1]. In spite of some problems, there are many benefits in this treatment process, more over approximately 15\% - 20\% of collected follicles are immature, in the other words, more collected follicles are in germinal vesicle (GV) stage [2,3]. In vitro techniques were used for research, genetic improvement or commercial purposes and the successful embryo production largely depends on the components of culture media during oocyte maturation $[3,4]$.

The formation of reactive oxygen species (ROS) is a natural process that happens in the cell during electron transfer reactions. Cellular molecules such as lipids, proteins and nucleic acids are altered by ROS [5]. In the recent stud- ies different antioxidants such as ß-mercaptoethanol ( ME), cysteine, cysteamine [6] and anthocyanin were used to supplement IVM of oocyte [7]. In the present time, there is an excessive interest in natural antioxidants instead of synthetic types, which may contribute to prevent oxidative damages [5].

For many years, the medicinal herbs have been used for treatment of several diseases in animals and humans [8]. During the last decades, an increasing interest in natural antioxidants consumption has arisen as a result of emerging concerns related to the synthetic chemicals side effects. This subject has increased the consumption of natural antioxidants derived from plants and marine sources $[9,10]$. Recently, seaweeds and marine invertebrates are well recognized as sources of natural metabolite which often suggested against more diseases such as cancer [11].

Scare information is reported about antioxidant properties of crude extracts from marine organisms [12]. 
Among marine invertebrates, sea cucumbers are well known to demonstrate advantageous effects on human health. Black sea cucumbers or Holothuria leucospilota are marine invertebrates of the phylum of echinoderms with a long body and leathery skin that have been used in Asian traditional medicine since ancient times [13]. Several studies have shown multiple biological activities of sea cucumber such as wound healing and antimicrobial, anticancer, anti-nociceptive and immune-modulatory properties [14].

Holothuria leucospilota generally distributed from the Red Sea to Hawaii, eastern Pacific (Is. Clarion, Socorro, Galapagos); widespread in the tropical Indo-Pacific and Conand ; tropical, Indo-Malayan Region, Pacific Ocean, E Africa, depth range $0-10 \mathrm{~m}$.

Recent studies have shown that the use of natural antioxidants could exert significant effect as therapeutic strategy in several human diseases mediated by oxidative stress [15].

It is indicated that during in vitro oocyte maturation, the levels of antioxidants have been reduced as compared with in vivo condition, therefore, the addition of a natural antioxidant to the medium may be appreciable for in vitro oocyte maturation [16].

\section{Objectives}

Hence, by considering the antioxidant capacity of sea cucumber and lack of documents regarding promoting effect of sea cucumber on oocyte maturation, this study was conducted to determine the effect of sea cucumber alcoholic extract on in vitro maturation of mouse oocyte.

\section{Methods}

\subsection{Animals}

In this experimental study, immature female Novel Medical Research Institute (NMRI) mice, 24 - 26 days purchased from Razi Institute, Mashhad, Iran and used in this study. They were housed in $23-25^{\circ} \mathrm{C}$ temperature in a pathogen free condition and in a light-controlled room (12 hours light: dark cycle) and fed pellet food (Javaneh Khorasan, Iran) and water ad libitum. All procedures in this study on animals exerted on the basis of ethic approval from Kharazmi Institute, Islamic Azad University of Mashhad.

\subsection{Preparation of Sea Cucumber Extract}

Persian Gulf sea cucumber Holothuria leucospilota Brandt (H. leucospilota) was collected from the coast of
Qeshm, Iran and immediately put on ice and was transferred to Mashhad university research laboratory. Collected sea cucumbers was dried in darkness after expelling the body contents and then crushed into small segments. For extraction, $10 \mathrm{~mL}$ methanol was added to each gram of dried sea cucumber for 72 hours. Then, filtration was performed and extract was concentrated in the vacuum evaporator (Heidolph, Germany) [17].

\subsection{Collection of Preantral Follicles}

Female mice (24 - 26 days) were euthanized by cervical dislocation and early preantral follicles with diameter, 120 $150 \mu \mathrm{m}$, were mechanically isolated from the ovaries using a 30-gauge needle under a stereomicroscope.

\subsection{In Vitro Preantral Follicle Culture}

The follicle culture medium consisted of $\alpha$ - MEM Gibco) supplemented with 5\% FBS, 100 units/mL penicillin, $100 \mu \mathrm{g} / \mathrm{mL}$ streptomycin, $5 \mu \mathrm{g} / \mathrm{mL}$ insulin, $5 \mu \mathrm{g} / \mathrm{mL}$ transferrin and $5 \mathrm{ng} / \mathrm{mL}$ selenium (ITS: Gibco). Then, $100 \mathrm{IU} / \mathrm{mL}$ follicular stimulating hormone (rhFSH: MerekSeronoSwitzerland) was added to the basal medium in the in vitro follicle culture for developing follicles. Follicles were individually cultured in a 24 -well plate containing 1 mL culture medium for 13 days. Subsequently, follicular growth was monitored every 2 days $(2,4,6,8,10$, and 12) under an inverted microscope at $200 \times$ magnification. Photomicrograph was captured by a camera system (DP-50: Olympus, Tokyo, Japan) and follicle diameter was measured using Image J software version 1.43 (National Institutes of Health, Bethesda, MD). When follicles clearly formed an antral like cavity on day 12, ovulation and meiotic resumption were induced by refreshing media with culture media supplemented with $5 \mathrm{IU} / \mathrm{mL}$ human chorionic gonadotropin (HCG). On day 13, follicles were checked for ovulation $16 \mathrm{~h}$ after hCG administration and ovulation was considered when the follicle was visually ruptured and the cumulus oocyte complex (COC) extruded from the follicles [18].

\subsection{Assessment of Follicle Parameters}

The follicular parameters such as survival, degeneration, \% of germinal vesicle and oocyte maturation were determined under inverted microscope during the culture program. At the beginning, granulosa cell proliferation is limited and theca cells grow out to the culture plate. The follicles remain in this stage until day 4 of culture. Marked granulosa cell proliferation and a large preantral follicle define the diffuse stage. From day 4 to day 6 of culture, granulosa cells overgrowth the theca cell monolayer 
through the basement membrane and the follicles regularly expanded. From day 6 or 8 up to day 12 of culture, the follicles form an antral-like cavity, which characterizes the antral stage. In this culture system, surviving follicles were determined as those that could preserve their oocyte completely embedded within the granulosa cell mass and that exhibited no signs of degeneration $[19,20]$.

\subsection{Determination of Antioxidant Capacity by DPPH Scaveng- ing Assay}

Radical scavenging abilities of the extracts were measured by using the stable radical 2, 2-diphenyl-2picrylhydrazyl (DPPH), based on the method of described previously [21]. The free radical scavenging activity of the extract was determined by using the DPPH assay. Then the methanol extracts $(500 \mu \mathrm{L})$ was added to $500 \mu \mathrm{L}$ solution of DPPH in methanol. After the reaction was allowed to take place in the darkroom for $30 \mathrm{~min}$ at room temperature, the absorbance at $517 \mathrm{~nm}$ was recorded to determine the concentration of remaining DPPH. BHT was considered as positive control. The radical scavenging activity was calculated as follows:

Scavenging activity $(\%)=\left[\left(\frac{\text { Ab control }- \text { Ab sample }}{\text { Ab control }}\right)\right]$

\subsection{Evaluating the Expression of TNF- $\alpha$ by Flow Cytometry}

For evaluating TNF- $\alpha$ expression in granulosa cells, flow cytometry analysis was used. In this assay, the treated and untreated granulosa cells were trypsinized and transferred to centrifuge in $2000 \mathrm{rpm}$ at $4^{\circ} \mathrm{C}$. Then rinsed with PBS and centrifuged again, and were added primary TNF$\alpha$ antibody (Abcam, UK) (1:100) overnight. On the next day, washing and centrifugation was performed, then secondary antibody conjugated with FITC (1:20) was added for 45 minutes. Finally, $300 \mu \mathrm{L} 0.1 \%$ formalin was added and flow cytometry was conducted using FACS caliber flow cytometry (Becton Dickinson, USA) [22].

\subsection{Statistical Analysis}

SPSS 16 were applied for all statistical analysis. Data were analyzed by one-way analysis of variance (ANOVA).Significant differences between treatments were determined by Duncan's multiple range tests. All of the data are expressed based on mean \pm SD. $\mathrm{P}<0.05$ was considered statistically significant.

\section{Results}

\subsection{Assessment of Follicle Parameters}

The follicle morphology is evaluated and the follicular development stage is classified as follicular, diffuse or antral in the in vitro preantral follicle culture. The percentage of arrested oocytes at GV stage in the control group was significantly $(\mathrm{P}<0.05)$ higher than treated group with $20 \mu \mathrm{g} / \mathrm{mL}$ sea cucumber extract. Oocytes treated with 20 $\mu \mathrm{g} / \mathrm{mL}$ showed the minimum percentage of GV stage compared with control, 5, 10 and $30 \mu \mathrm{g} / \mathrm{mL}$ sea cucumber extract $(\mathrm{P}<0.05)$; however, no significant difference observed at percentage of GV stage between control and treatment groups. Significant differences were found between treated $(10,20 \mu \mathrm{g} / \mathrm{mL})$ and control groups in follicle diameter $(\mathrm{P}<0.05)$. The percentage of antral like cavity formation in treated group $(20 \mu \mathrm{g} / \mathrm{mL})$ was significantly (P $<0.05$ ) higher than control and treatment groups. There was significant $(\mathrm{P}<0.01)$ difference between treated group with $20 \mu \mathrm{g} / \mathrm{mL}$ extract and the control in percentage of maturated oocytes to metaphase II (MII) stage. In addition, significant differences were found between treated group with $10 \mu \mathrm{g} / \mathrm{mL}$ sea cucumber extract and control group in maturated oocytes percentage to metaphase II (MII) stage $(\mathrm{P}<0.05)$. The oocytes treated with $20 \mu \mathrm{g} / \mathrm{mL}$ extract achieved the maximum percentage of MII stage and antrum formation compared to control group. There were no significant differences in the percentage of MII stage in treated groups $(5,30 \mu \mathrm{g} / \mathrm{mL})$ and control group (P $>0.05$ ) (Table 1) (Figures 1 and 2).

\subsection{Determination of Antioxidant Capacity}

The anti-oxidative potential of sea cucumber alcoholic extract was evaluated using the DPPH free radical scavenging assay. Figure 3 showed that sea cucumber dose dependently exerted DPPH scavenging effect with $51.9 \%$ scavenging capacity in a concentration of $1 \mathrm{mg} / \mathrm{mL}$. Therefore, depending on concentration, the methanol extract exhibited a moderate DPPH-scavenging activity as compared to the BHT as a standard antioxidant compound.

\subsection{Evaluating the Expression of TNF- $\alpha$ by Flow Cytometry}

We examined whether sea cucumber extract can exert its promoting effect via inhibition of TNF- $\alpha$ or not. Flow cytometry diagrams revealed that sea cucumber extract significantly down regulated TNF- $\alpha$ expression level in a dosedependent manner. TNF- $\alpha$ level in control group was 55.2\% and in sea cucumber treated group (10 and $20 \mu \mathrm{g} / \mathrm{mL}$ ) was $14.7 \%, 6.7 \%$ respectively. These results indicated that sea cucumber extract in concentrations of 10 and $20 \mu \mathrm{g}$ significantly reduced TNF- $\alpha$ which is related with ovulation stage (Figure 4). 
Table 1. Effect of Different Concentration of Sea Cucumber Extract on IVM Rate ${ }^{\mathrm{a}, \mathrm{b}}$

\begin{tabular}{|c|c|c|c|c|c|c|}
\hline Different concentration of sea cucumber, $\mu \mathrm{g} / \mathrm{mL}$ & Total & Viability \% & Degeneration \% & GV\% & Antrum \% & Maturation \% \\
\hline o & 123 & $63 \pm 4.58$ & $36 \pm 5.56$ & $47 \pm 4.00$ & $41 \pm 4.35$ & $29 \pm 3.66$ \\
\hline 5 & 78 & $64 \pm 5.00$ & $36 \pm 5.56$ & $48 \pm 5.56$ & $43 \pm 6.00$ & $32 \pm 5.56$ \\
\hline 10 & 73 & $71 \pm 7.21$ & $29 \pm 5.56$ & $41 \pm 5.56$ & $47 \pm 5.56$ & $48 \pm 8.54$ \\
\hline 20 & 81 & $78 \pm 5.56$ & $22 \pm 4.58$ & $33 \pm 2.51$ & $57 \pm 2.64$ & $53 \pm 4.00$ \\
\hline 30 & 83 & $59 \pm 3.60$ & $41 \pm 3.60$ & $46 \pm 4.35$ & $46 \pm 4.35$ & $41 \pm 5.29$ \\
\hline
\end{tabular}

${ }^{\mathrm{a}}$ Data are expressed as mean $\pm \mathrm{SD}$.

${ }^{\mathrm{b}}$ Percentage of viability, oocytes arrested at germinal vesicle (GV), oocytes at antral-like cavity stages and metaphase II oocytes (MII) stage; All experiments were repeated eight times.
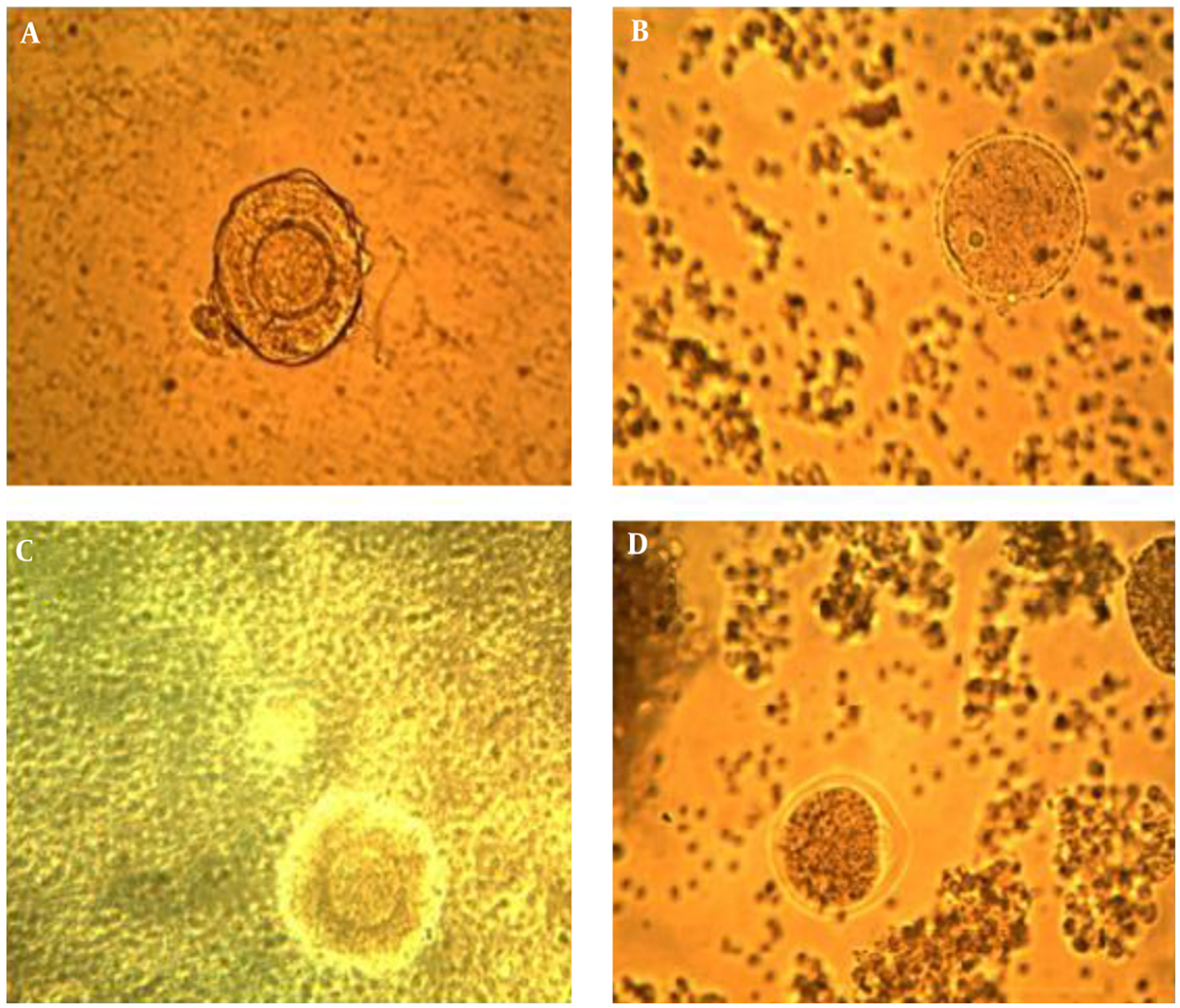

Figure 1. A, Preantral Follicle; B, Germinal Vesicle (GV) Stage; C, Granulosa Cell; D, Oocyte Maturation (Polar Body)

\section{Discussion}

To our knowledge, this study is the first report to prove the advantageous effect of sea cucumber extract as supplementation micro-environment in IVM. In this study, the DPPH scavenging effect of sea cucumber extract proposed antioxidant capacity of this extract which conferred potential to counteract with stress oxidative. The reactive oxygen species (ROS) and free radical generation induced oxida- tive stress that possess a damaging effect on early in vitro embryo development [23].

Althunibat et al. [24] exhibited that sea cucumber various species reduced the levels DPPH and suggested that sea cucumber are proposed as potential sources of natural antioxidant which in accordance to our study, demonstrated antioxidant potential of sea cucumber species. Esmat et al. [25] reported that Red Sea (H. atra) possess physiologi- 
Figure 2. A, Effect Ofsea Cucumber Extract on Viability of Oocyte; B, Degeneration; C, Oocyte Arrested at Germinal Vesicle (GV)Stage; D, Oocyte at Antral-Like Stages; E, Metaphase II Oocyte (MII) Stage

A

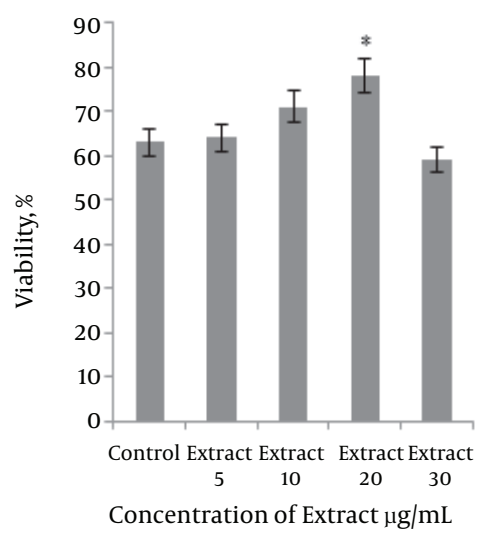

B

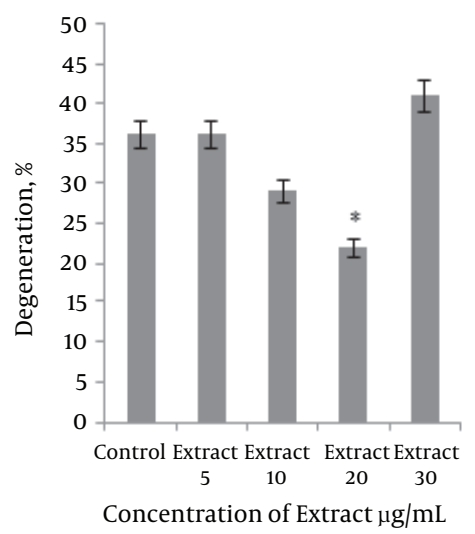

C

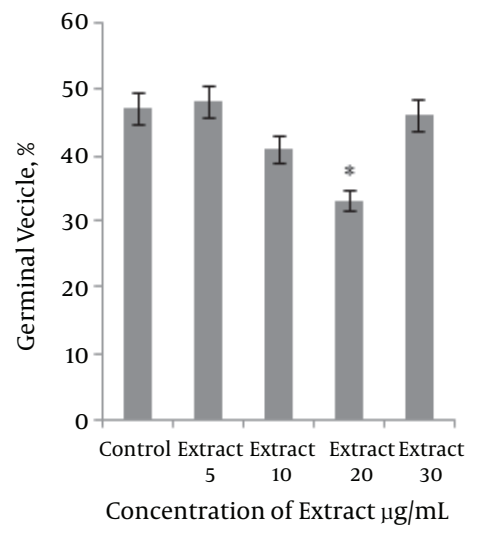

D

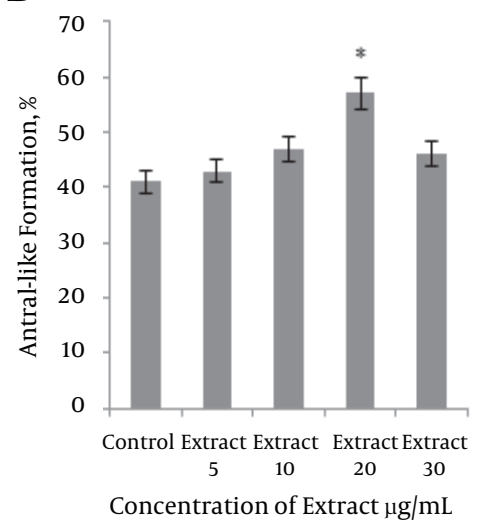

$\mathbf{E}$

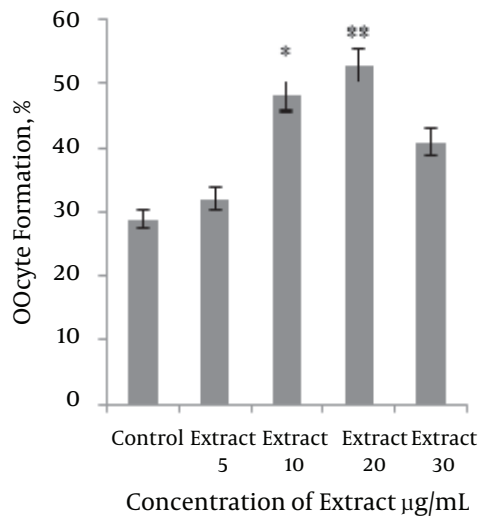

Sea cucumber extract (optimum concentration of $20 \mu \mathrm{g} / \mathrm{mL}$ ) promoted in vitro maturation indicators via reduction of GV stage, increment of antral like and MII stage. The data were represented as mean $\pm S D$ and ${ }^{*} \mathrm{P}<0.05,{ }^{*} \mathrm{P}<0.01$ were considered significant.

Figure 3. Comparative Effect of Methanol Extract and BHT on DPPH Assay

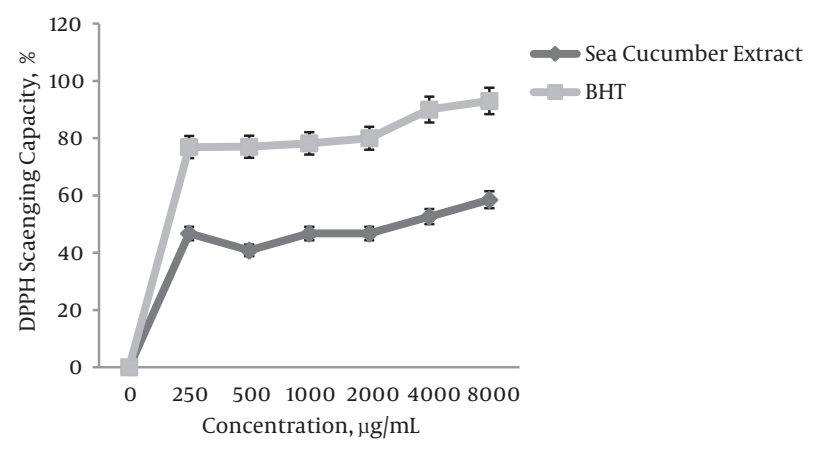

Methanol extract of sea cucumber showed significant radical scavenging effect. 50 $\%$ inhibitory concentrations of sea cucumber extract was $1000 \mu \mathrm{g} / \mathrm{mL}$ as compared with $<250 \mu \mathrm{g} / \mathrm{mL}$ of BHT as positive control. cally active phenolic compounds with antioxidant capacity which afforded a potential hepato-protective activity against thioacetamide induced liver injury in a rat model. These findings in agreement with our results confirmed antioxidant potential of sea cucumbers which promoted pre antral follicle in vitro maturation.

On the other hand, the present study assessed the supplementation effects of sea cucumber methanol extract on the follicular development and IVM of mouse oocyte. The beneficial effect of natural extract on in vitro maturation has been demonstrated previously [26]. Our results showed that the addition of optimum concentration of sea cucumber methanol extract during IVM process enhanced the percentage of in vitro maturated oocyte to MII stage. This means that addition of an appropriate concentrations of sea cucumber methanol extract in maturation medium 
Figure 4. Flow Cytometry Analysis of TNF- $\alpha$ Expression

A

A $0.5 \%$

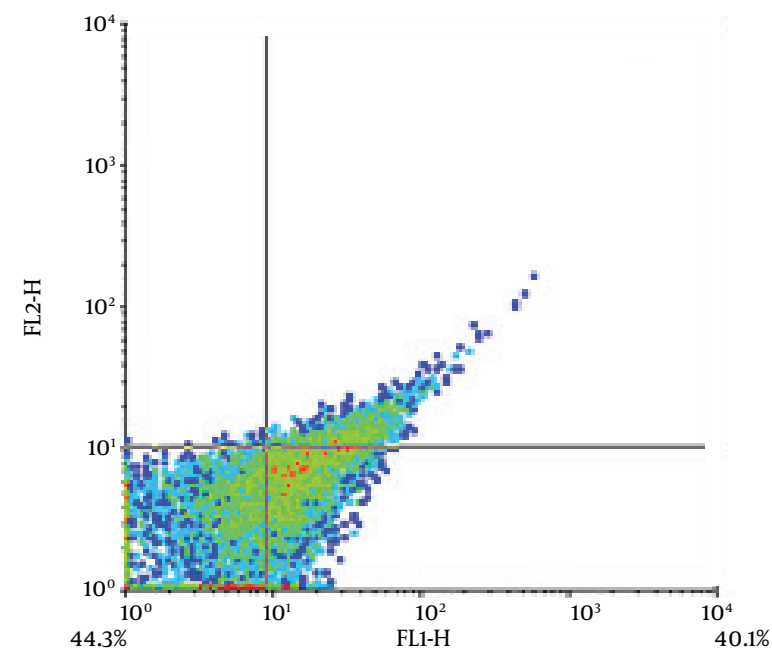

B

$0.5 \%$

$2.4 \%$

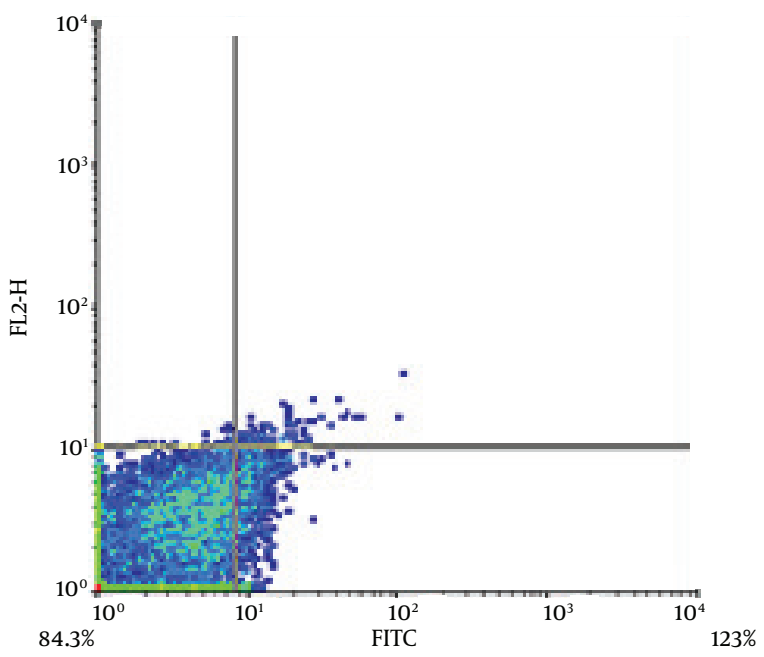

C

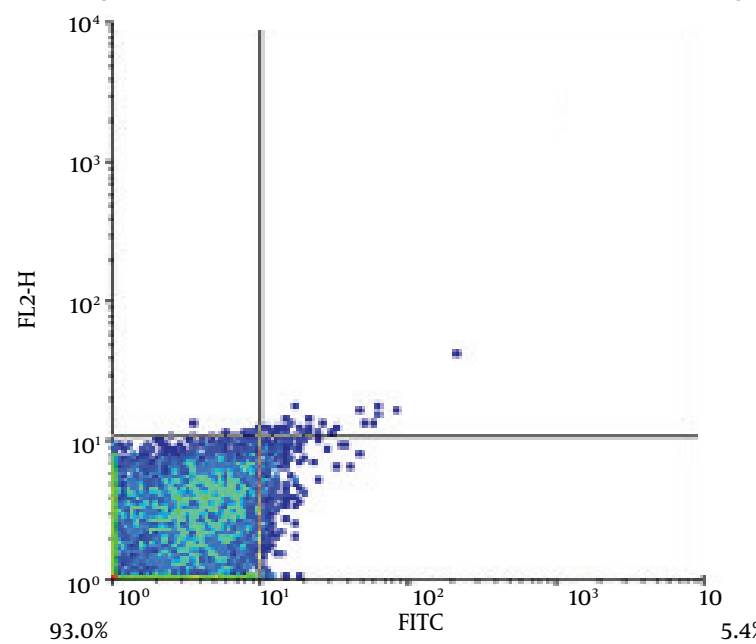

Sea cucumber extract reduced the expression of TNF- $\alpha$. A) Control (55.2\%). B) Treated group with $20 \mu \mathrm{g} / \mathrm{mL}$ sea cucumber extract (36.3\%). C) Treated group with $10 \mu \mathrm{g} / \mathrm{mL}$ sea cucumber extract (6.7\%)

have beneficial effects on IVM of mouse oocyte. The oocyte treated with $20 \mu \mathrm{g} / \mathrm{mL}$ extract achieved the highest percentage of in vitro maturated oocyte to MII stage.

It was demonstrated that supplementation of green tea polyphenols (GTP) during maturation of bovine oocyte increased blastocyst formation [27]. Moreover, In vitro culture of mouse oocyte in maturation medium with saffron (Crocus sativus L.) extract increased maturation and fertilization rate of oocyte [26]. It has been shown that the optimum concentration of Papaver rhoeas extract (100 $\mu \mathrm{g} / \mathrm{mL}$ ) in mouse oocyte maturation medium improves the rate of oocyte maturation and subsequently enhanced the rate of embryo development [28]. Rajabi-Toustani et al. [16] showed that Papaver rhoeas extract enhanced maturation rate of follicls dependent on the extract concentration, so that $\mathrm{P}$. rhoeas extract with an appropriate concentrations $(50 \mu \mathrm{g} / \mathrm{mL})$ in maturation medium elevated the sheep oocyte maturation rate, while the results of this investigation elucidated the beneficial effect of natural extracts such as sea cucumber as supplementation in IVM 
process. Further, it is suggested that these beneficial effects are possibly related to their polyphenols contents (such as flavonoids and anthocyanin) that are the major compounds in this plant which is considered as the main reason of administrating antioxidant activity [27, 29]. These investigations in consistent with our results implied that natural substances possessing antioxidant capacity may be proposed as an appropriate supplement for in vitro maturation.

TNF- $\alpha$ is a pro-inflammatory cytokine that induces cell death. It was previously demonstrated that TNF- $\alpha$ significantly inhibited FSH-induced follicular development and steroidogenesis, therefore, TNF- $\alpha$ expression level was utilized for evaluation of follicular development [30]. In this in vitro study, we indicated that TNF- $\alpha$ protein level significantly inhibited under treatment with sea cucumber extract which proved that sea cucumber extract improved follicular development and maturation.

In addition, the results of this study showed that supplementation of appropriate concentrations of sea cucumber extract $(20 \mu \mathrm{g} / \mathrm{mL})$ in maturation medium improve the mouse oocyte maturation rate. However, the higher rate of mice oocyte maturation indicated that the improving effect of sea cucumber on oocyte development was related with antioxidant potential and down regulation of TNF- $\alpha$ protein expression level as degenerative follicular factor.

Nabiuni et al. [22] indicated that supplementation of in vitro maturation medium with natural antioxidants and anti-inflammatory agents such as bee venom improved maturation rate of mice preantral follicles which is associated with down regulation of TNF- $\alpha$ factor as necrosis inflammatory factor. Meanwhile, our findings confirmed improvement of preantral follicles maturation rate attributed with reduction of TNF- $\alpha$ expression.

In conclusion, the results of this investigation proved that the addition of marine natural extracts to maturation medium which possess natural antioxidants was innocent and can be useful in this field possibly by minimum side effects of synthetic material. Accordingly, sea cucumber may be regarded as a valuable source of bioactive compound for drug discovery in biomedicine.

\section{Acknowledgments}

The authors would like to thank from research center of animal development applied biology, Islamic Azad University, Mashhad, Iran. This project (code of 11130517921007) financially supported by Islamic Azad University of Mashhad.

\section{Footnotes}

Authors' Contribution: Design was performed by Javad Baharara and Mohsen Jalali; work was conducted by Mitra Khalilzadeh, Javad Baharara and Elaheh Amini; statistical analysis was performed by Farideh Namvar and manuscript writing was performed by Javad Baharara, Elaheh Amini and Mitra Khalilzadeh.

Funding/Support: Research center for animal development applied biology, Mashhad Branch, Islamic Azad University.

\section{References}

1. Tao P, Coates R, Maycock B. Investigating marital relationship in infertility: a systematic review of quantitative studies. J Reprod Infertil. 2012;13(2):71-80. [PubMed: 23926528].

2. Reichman DE, Politch J, Ginsburg ES, Racowsky C. Extended in vitro maturation of immature oocytes from stimulated cycles: an analysis of fertilization potential, embryo development, and reproductive outcomes. J Assist Reprod Genet. 2010;27(7):347-56. doi: 10.1007/s10815010-9416-5. [PubMed: 20425141].

3. Farsi MM, Kamali N, Pourghasem M. Embryological aspects of oocyte in vitro maturation. Int J Mol Cell Med. 2013;2(3):99-109. [PubMed: 24551799].

4. Farsi MM, Jorsaraei SG, Esmaelzadeh S, Golaipour MJ. In vitro maturation of germinal vesicle oocytes in stimulated intracytoplasmic sperm injection cycles. Cell J. 2011;13(2):73-8. [PubMed: 23508330].

5. Rajabi-Toustani R, Motamedi-Mojdehi R, Roostaei A, MotamediMojdehi R. Effect of papaver rhoeas L. extract on in vitro maturation of sheep oocytes. Small Rumin Res. 2013;114(1):146-51.

6. Kobayashi M, Lee ES, Fukui Y. Cysteamine or beta-mercaptoethanol added to a defined maturation medium improves blastocyst formation of porcine oocytes after intracytoplasmic sperm injection. Theriogenology. 2006;65(6):1191-9. doi: 10.1016/j.theriogenology.2005.06.019. [PubMed:16154628].

7. You J, Kim J, Lim J, Lee E. Anthocyanin stimulates in vitro development of cloned pig embryos by increasing the intracellular glutathione level and inhibiting reactive oxygen species. Theriogenology. 2010;74(5):777-85. doi: 10.1016/j.theriogenology.2010.04.002. [PubMed: 20537699].

8. Al-maeeni IM, Samaree KW, Abdulrahman LY. Study the effect of addition alcoholic extract of Tribulus terrestris on bovine oocyte maturation in vitro ( IVM ). Iraqi JVet Med. 2012;36(2):199-203.

9. Inoue T, Ono Y, Yonezawa Y, Oi M, Kobayashi N, Kishi J. Oocyte quality improvement using a herbal medicine comprising 7 crude drugs. Open J Obstetrics Gynecol. 2013:195-202.

10. Ushiroyama T, Yokoyama N, Hakukawa M, Sakuma K, Ichikawa F, Yoshida S. Clinical efficacy of macrophage-activating Chinese mixed herbs (MACH) in improvement of embryo qualities in women with long-term infertility of unknown etiology. Am JChin Med. 2012;40(1):110. doi: 10.1142/S0192415X12500012. [PubMed: 22298444].

11. Jha RK, Zi-rong X. Biomedical compounds from marine organisms. Mar Drugs. 2004;2(3):123-46.

12. Mamelona J, Pelletier E, Girard-Lalancette K. Quantification of phenolic contents and antioxidant capacity of Atlantic sea cucumber, $\mathrm{Cu}$ cumaria frondosa. Food Chem. 2007;104(3):1040-7.

13. Althunibat OY, Ridzwan BH, Taher M, Daud JM, Jauhari Arief Ichwan S, Qaralleh H. Antioxidant and cytotoxic properties of two sea cucumbers, Holothuria edulis lesson and Stichopus horrens Selenka. Acta Biol Hung. 2013;64(1):10-20. doi: 10.1556/ABiol.64.2013.1.2. [PubMed: 23567827]. 
14. Osama YA, Ridzwan BH, Muhammad T, Jamaludin MD, Masa-Aki I. In Vitro Antioxidant and Antiproliferative Activities of ThreeMalaysian Sea Cucumber Species. European J Sci Res. 2009;37(3):376-87.

15. Zhang X, Gao F. Natural antioxidants for health promotion and disease prevention. Ethnopharmacol. 2014;266(5):679-86.

16. Rajabi-Toustani R, Motamedi-Mojdehi R, Roostaei-Ali Mehr M, Motamedi-Mojdehi R. Effect of Papaver rhoeas L. extract on in vitro maturation of sheep oocytes. Small Ruminant Res. 2013;114(1):146-51.

17. Baharara J, Amini E, Kerachian MA, Soltani M. The osteogenic differentiation stimulating activity of Sea cucumber methanolic crude extraction on rat bone marrow mesenchymal stem cells. Iran JBasic Med Sci. 2014;17(8):626-31. [PubMed: 25422758].

18. Hara S, Takahashi T, Amita M, Matsuo K, Igarashi H, Kurachi H. Pioglitazone counteracts the tumor necrosis factor-alpha inhibition of follicle-stimulating hormone-induced follicular development and estradiol production in an in vitro mouse preantral follicle culture system. J Ovarian Res. 2013;6(1):69. doi: 10.1186/1757-2215-6-69. [PubMed: 24079935].

19. Adriaenssens T, Mazoyer C, Segers I, Wathlet S, Smitz J. Differences in collagen expression in cumulus cells after exposure to highly purified menotropin or recombinant follicle-stimulating hormone in a mouse follicle culture model. Biol Reprod. 2009;80(5):1015-25. doi: 10.1095/biolreprod.107.067462. [PubMed: 19164180].

20. Soltani M, Baharara J. Antioxidant and antiprolifereative capacity of dichloromethane extract of holoturia leucospilota sea cucumber. Int J Mol Cell Med. 2014;20(14):1-9.

21. Abdo M, Hisheh S, Arfuso F, Dharmarajan A. The expression of tumor necrosis factor-alpha, its receptors and steroidogenic acute regulatory protein during corpus luteum regression. Reprod Biol Endocrinol. 2008;6:50. doi: 10.1186/1477-7827-6-50. [PubMed: 18990246].

22. Nabiuni M, Kakai M, Nazari Z, Karimzadeh L. Effect of honey bee venom on in vitro maturation of preantral follicles in NMRI mice [ in persian]. J Sci Kharazmi Uni. 2013;13(1):749-60.

23. Barakat IAH, Hassan AM, Alam SS, Khalil WKB. Genetic and biochemical effects of natural extracts on in Vitro maturation of Egyptian buffalo oocytes. Cytologia. 2010;75(3):243-53.

24. Althunibat OY, Hashim RB, Taher M, Daud JM, Aki M. In Vitro Antioxidant and Antiproliferative Activities of Three Malaysian Sea Cucumber Species. Eur J Sci Res. 2009;37(3):376-87.

25. Esmat AY, Said MM, Soliman AA, El-Masry KS, Badiea EA. Bioactive compounds, antioxidant potential, and hepatoprotective activity of sea cucumber (Holothuria atra) against thioacetamide intoxication in rats. Nutrition. 2013;29(1):258-67. doi: 10.1016/j.nut.2012.06.004. [PubMed: 23085016].

26. Tavana S, Eimani H, Azarnia M, Shahverdi A, Eftekhari-Yazdi P. Effects of Saffron (Crocus sativus L.) Aqueous Extract on In vitro Maturation, Fertilization and Embryo Development of Mouse Oocytes. Cell J. 2012;13(4):259-64. [PubMed: 23507933].

27. Wang ZG, Yu SD, Xu ZR. Improvement in bovine embryo production in vitro by treatment with green tea polyphenols during in vitro maturation of oocytes. Anim Reprod Sci. 2007;100(1-2):22-31. doi: 10.1016/j.anireprosci.2006.06.014. [PubMed: 16870363].

28. Golkar-Narenji A, Eimani H, Samadi F. Effect of Papaver rhoeas extract on in vitro maturation and developmental competence of immature mouse oocytes. Reprod Med Biol. 2010;9:211-5.

29. Du G, Li M, Ma F, Liang D. Antioxidant capacity and the relationship with polyphenol and vitamin $\mathrm{C}$ in Actinidia fruits. Food Chem. 2009;113:557-62.

30. Hara S, Takahashi T, Amita M, Igarashi H, Tsutsumi S, Kurachi H. Bezafibrate restores the inhibition of FSH-induced follicular development and steroidogenesis by tumor necrosis factor-alpha through peroxisome proliferator-activated receptor-gamma pathway in an in vitro mouse preantral follicle culture. Biol Reprod. 2011;85(5):895-906. doi: 10.1095/biolreprod.111.090738. [PubMed: 21734263] 